Mappemonde

Revue trimestrielle sur l'image géographique et les

formes du territoire

$119 \mid 2017$

Varia

\title{
Promenade en Touraine
}

Jean-Christophe Gay

\section{OpenEdition}

\section{Journals}

Édition électronique

URL : http://journals.openedition.org/mappemonde/2376

DOI : $10.4000 /$ mappemonde.2376

ISSN : 1769-7298

Éditeur

UMR ESPACE

\section{Référence électronique}

Jean-Christophe Gay, «Promenade en Touraine », Mappemonde [En ligne], 119 | 2017, mis en ligne le 01 janvier 2017, consulté le 24 septembre 2020. URL : http://journals.openedition.org/mappemonde/ 2376 ; DOI : https://doi.org/10.4000/mappemonde.2376

Ce document a été généré automatiquement le 24 septembre 2020.

\section{(c) (i) (2)(2)}

La revue Mappemonde est mise à disposition selon les termes de la Licence Creative Commons Attribution - Pas d'Utilisation Commerciale - Partage dans les Mêmes Conditions 4.0 International. 


\section{Promenade en Touraine}

Jean-Christophe Gay

\section{RÉFÉRENCE}

Roger Brunet, Atlas de la Touraine. La Crèche : Geste éditions, 253 p. ISBN

978-2-36746-499-2 
1 Roger Brunet nous propose une promenade à la fois savante et touristique en Touraine, cette ancienne province qui correspond aujourd'hui, grosso modo, au département d'Indre-et- Loire, légèrement plus à l'ouest que la province si on veut être précis. Dans son esprit et son iconographie, ce livre rappelle la collection « Découvrir la France », publiée entre 1972 et 1974 chez Larousse, sous la direction de Roger Brunet, et qui fut un grand succès de librairie. C'est tout le bien que nous souhaitons à cet ouvrage aux nombreuses photographies et à la cartographie abondante et de qualité, qui comblera les Tourangeaux en quête d'informations sur leur territoire et les autres, spécialement géographes, en manque d'études synthétiques à cette échelle-là. Les cartes choroplèthes des communes d'Indre-et-Loire à partir des derniers chiffres du recensement de la population ou des services fiscaux, par exemple, permettent de comprendre les disparités au sein de ce département "normal » sur le plan de la population et de la superficie, qui ne se distingue vraiment de la moyenne nationale qu'à propos de la faible place des résidences secondaires et celle des étrangers ou immigrés. On trouve aussi quelques chorotypes et des croquis de synthèse à des échelles variées, nationale, régionale, départementale, infra-départementale, cantonale, communale ou des quartiers de Tours. Dans une logique diachronique et synchronique, cinquante pages sont consacrées à cette ville et à son agglomération, qui rassemble plus de la moitié de la population départementale. La suite du livre, soit environ la moitié de celui-ci, est une série de monographies communales organisée par pays et petits espaces qu'il n'est pas toujours facile de localiser quand on ne connaît pas bien cet ensemble. Ainsi le Chinonais, le Langeaisien, le Bourgueillois, le pays de Racan, le val d'Amboise, le Castelrenaudais, le pays de Loches, le Ligueillois, etc. sont explorés et plus de 270 communes ont droit à une notice d'une huitaine de lignes au minimum. On reconnaîtra les informations contenues dans la remarquable base en ligne France, le trésor des régions, constituée par l'auteur sur l'ensemble du territoire national, outremer inclus, et dont il a actualisé les données pour cet Atlas de la Touraine.

\section{AUTEURS}

\section{JEAN-CHRISTOPHE GAY}

Université Nice Sophia-Antipolis 